\title{
Sacrifice and Distinction in Dirty Work: Men's Construction of Meaning in the Butcher Trade
}

\section{Abstract}

Through a study of the butcher trade, this article addresses a neglected area in work and organization by exploring the meanings that men, working as employees, give to 'dirty work' i.e. jobs or roles that are seen as distasteful or 'undesirable'. Based on qualitative data, we identify three themes from butchers' accounts that relate to work based meanings: orthodoxy of work, acceptance and choice and physicality, dirt and loss. We argue that notions of sacrifice help us understand some of the meanings men attach to dirty, manual work forming part of a working class 'habitus' that crystallizes past, present and future. Further, we show how meanings relating to sacrifice are illustrative of ways of 'doing' working class masculinity in this context.

Key words: class, dirty work, masculinity, work meanings 


\section{Introduction}

This article explores the meanings working class men attach to 'dirty work': that is, to jobs or roles that are seen as distasteful or undesirable (Hughes, 1951; Douglas, 1966; Ashforth and Kreiner, 1999). Specifically, it considers the values that butchers, working as employees in a 'dirty' but highly regulated and changing trade (Ackroyd and Crowdy, 1990; Meara, 1974) place on their occupation's skills and practices. Work offers meanings that are less readily available from any other activity or institution - it gives time structures to the day, prompts contact with others and provides opportunity to participate in a collective activity or purpose thereby offering potential status and feelings of self-worth (Jahoda, 1982; Leidner, 2006). However, while recent research has considered aspects of meanings within the context of 'clean' white collar occupations often oriented around personal fulfilment and the manufacture of work-based identity - less is known about the meanings that men, as a 'classed' and gendered group, place on and/or draw from 'dirty' work (Cowan et al, 2011) and how they respond to changes in the way such work is carried out.

The butcher trade, as a male dominated occupation with traditionally 'masculine' connotations pertaining to animal slaughter (Adams, 2010), has potential to highlight key aspects of work that may have implications for meanings attached. Given the contact with blood and meat and the routine use of cutters and grinders, it conforms to Ashforth and Kreiner's (1999) notion of a 'physically tainted occupation', i.e. one that involves dirt or danger and so is generally viewed with 'distaste'. As a number of commentators have observed (for example, Hughes, 1958; Dick, 2005; Ashforth and Kreiner, 1999; Author 1 et al, 2012), such work has potential to damage feelings of self-worth and is often carried out by those at 'lower levels' of the social hierarchy . Further, intense competition from supermarkets and the effects of greater public regulation have meant that the butcher trade is both declining in importance and becoming 'cleaner' in terms of work practices - raising questions about how men might accordingly revalue their work. The trade thus presents a prime empirical opportunity for an exploration of how men both draw upon and create meanings as they seek to establish dignity and respect in an uncertain and changing context where, shared by many manual workers, both may be under threat. 
As Leidner (2006) has argued, an understanding of work based meanings must incorporate individual 'habits of mind' (Jahoda, 1982) as well as the social context in which such work is carried out. To capture this interplay and to make sense of and situate such meanings within a set of gender and class based practices and values, we draw on Bourdieu's $(1984 ; 1990)$ notion of 'habitus'. This refers to sets of 'dispositions' informed by particular social and cultural conditions, or 'fields', that structure judgement and practices and which, together, generate value to different forms of capital (Bourdieu, dates). As Emirbayer and Johnson (2008) have argued, while Bourdieu's concepts of field and capital have been extensively employed in organisational analysis, his concept of habitus remains rather less well utilised, particularly in ways that are consistent with the broader relational orientation that Bourdieu sought to advance. We provide a research based illustration, in consistency with Bourdieu's anti-substantialism, that meanings and judgements are integral aspects of an emergent social habitus that has shifted with the configuration of relationships in which it has been constituted. Thus, in a field structured by changing work practices as well as, from Skeggs (1997; 2004a), by constrained choice and limited opportunity - and in addressing the central question 'what meanings do butchers working as employees ascribe to their work?' - we argue that notions of sacrifice (hard work, endurance)and of distinction (from others in the trade) underpin the meanings ascribed to such work. These partly form and are partly informed by aspects of a durable working class habitus. In so doing, we contribute to literatures on meanings associated with 'dirty work' - types of labour that have hitherto been neglected in organizational research (Ashforth and Kreiner, 1999; Ashforth et al, 2007) as well as to understandings of current manifestations of working class masculinity (e.g. Charlesworth, 2000; McDowell, 2003; Thiel, 2007) an area that has been largely invisible within contemporary accounts of work and organizations (Gregg and Wadsworth, 2003; Nixon, 2009; Skeggs, 2004a; McDowell, 2003).

\section{Work-Based Meanings and Working Class Men}

While early orientations placed work and its meanings within macro level structures and systems of capitalism, other perspectives (see Leidner, 2006 for a useful overview) have focused on the micro processes through which individuals seek to imbue work with value. In terms of the former, Marxist interpretations (e.g. 
Fromm, 1990; Bravermann, 1974) have positioned the repetitive, monotonous work of capitalism as devoid of intrinsic meaning through exploitative and alienating relations of production that, in Weberian terms, have called historically on religious beliefs to ascribe moral worth. From an ethnomethodological perspective, work meanings are seen as the outcome of interactions and self-presentations (e.g. Hughes, 1951; 1958; Ashforth and Kreiner, 1999) where dignity and worth can be created through shared occupational ideologies and through individual and collective negotiations that infuse work practices with specific value - while poststructuralists see meanings as fragile and unstable, reflecting individuals' ability to mobilise resources to construct and/or contest a particular ideological order and sense of self (Dick, 2005; Tracy and Scott, 2006).

For Bourdieu (dates), meanings and processes of meaning making do not just arise, unbounded, from social interactions but are partly structured by dynamic fields of possibility. Here, Bourdieu draws on his notion of habitus as a system of embodied and 'lasting disposable dispositions' (Bourdieu, date) perceptions and actions that are conditioned by social origin and shaped by the economic and cultural conditions of the field. Habitus refers to aspects of a group's culture or 'shared ethos' that are 'anchored' in the person - including the totality of learned habits, bodily skills, tastes, perceptions and assumptions that link past to present and thus to future potentiality. Here, individuals carry with them volumes of capital, displayed as dispositions, which are differentially evaluated and which have an alignment with social position and the 'specific logic' of the field. Here, emphasis is placed on the body as a form of physical capital i.e. on the size, shape and appearance of the flesh (Shilling, 2004) that converts into other resources (such as a living wage in manual work) and where its value is recognised in the context of social fields. Further, the power relations that characterize the field delineates a changing 'space of possibles' wherein individuals mobilize cultural distinctions from each other by means of 'symbolically meaningful position taking' (Emirbayer and Johnson, 2008) - such as attitudes, dress or deportment (Bourdieu, 1985). Thus, in a mutually constitutive sense, the field as a symbolic system ordered by a 'logic of difference' (Bourdieu, 1985) delineates a dynamic set of potentialities and capital distributions while the habitus gives rise to the possible position taking open to that person within the field - evaluating some positional forms as more desirable and/or more contestable than 
others. Meanings i.e. the perceptual configurations that arise from a symbolic order can thus be seen to be driven by individual perceptions and evaluations (e.g. of capital; of differential position-takings and distinctions) that in turn involve intersecting and overlapping social and cultural fields (Bourdieu, 1985). While this may arguably place priority on a 'world view' that is framed by background and training (Shilling, 2004; Skeggs, date) and an overly reproductionist orientation in terms of how meanings unfold (Shilling, 2004), Bourdieu's approach affords an analytical frame in which individual and broader contextual processes of meaning-making in relation to work can be incorporated into a unified scheme.

While not necessarily focussing explicitly on meanings, some research has uncovered aspects of values, attitudes and motivations that working class men attach to manual jobs. Here, waged work is often valued for the recognition and respect it affords in a context where primacy is attached to skill, effort and output, and where being an honest, hard-working employee are valorized as a means of creating dignity and moral worth (Willis, 1977; Charlesworth, 2000; Sennett and Cobb, 1972; Sayer,2005). Here, as Willis (1977) found, there is often little differentiation between types of work. Thus, each job or task carries minimal intrinsic meaning. Rather, meaning is sought through work as a whole e.g. through the avoidance of unemployment and the effort, strength and physical skill demanded (Willis, 1977; Connell, 2000; Wray-Bliss and Parker, 1998) as well as through a sense of camaraderie and shared bravado or 'shop floor humour' (Collinson, 1988)- reflective, potentially, of a worldly realism (Charlesworth, 2000) and of a 'continuing functionality' (Thiel, 2007) in working men's lives.

As Charlesworth (2000) and Skeggs $(1997,2004 a)$ suggest, these attitudes and values need to be located within a set of class relations and evaluations that position members of the working class as 'undeserving'. As they argue, working class lives are characterized by limited choice and opportunity with individuals often perceived as 'passive agents' (Sennett and Cobb, 1972) who misuse and/or waste the opportunities on offer. This has contemporary significance in a context where choices are seen to be freely available (Gabriel, 2005) and where, as Sennett argues (1998), the 'missed opportunity' appears as the ultimate failure. These moral 
evaluations 'make their mark' and attach firmly to working class identities (Sennett and Cobb, 1972; Roberts, 2001) - giving primacy, potentially, to the physicality of work as a source of alternative meanings. Thus, working class men often construct meaning around the difficulties of supporting families, a key priority, in what they perceive as a hostile world (Willis, 1977; McDowell, 2003) - mobilizing personal capacities of endurance, effort and fortitude to give value and purpose to work-based experiences (Sennett and Cobb, 1972; Connell, 2000; Ashforth and Kreiner, 1999

Read through Bourdieu $(1984 ; 1990)$ this helps us to conceive of a working class 'habitus' that is anchored on the body and which forms a 'mark' of social position and social difference - where that social location inculcates a set of tastes and perceptions (Bourdieu, 1980). The body is both a materialization of class and reveals the 'deepest dispositions' of the habitus where working class bodies carry symbolic value through strength and physical competence that are prized within the aesthetics of masculinity. Social conditions and dominant power relations of the 'field', reflected partly in moral judgments referred to above that help legitimize levels of entitlement, accordingly produce lived traditions, practices and values. Following this, while the habitus can be seen to influence the meanings assigned to work, they are also constituted within a set of (class based) social relations - raising issues about the potential continuity of meanings and how individuals may reproduce and create meanings in the context of a changing field.

\section{Dirt, Class and Butchery}

Those occupations which deal routinely with dirt may, as authors suggest (Ashforth and Kreiner, 1999; Dick, 2005; Tracy and Scott, 2006; Author 1 et al, 2012), present a particular challenge in terms of assigning meaning to work. As Douglas (1966) argued, our ideas of dirt, as impurity or 'matter out of place' (Douglas, 1966, p.45), contradict cherished classifications. Meat for example is treated as contagious and dirty because of its contradictory relations (Turner, 1996): animal flesh is something we reject yet desire - repulsive yet potentially enjoyable. From this perspective, cleanliness is about establishing boundaries, separating the pure from the contaminated, and imposing a system on an 'inherently untidy experience' (Douglas, 1966, p.85). Dirt also forms the basis for hierarchical difference. For Skeggs (2004a), dirt, danger and disorder serve as a 
signifier of class and as moral evaluations by which classes are coded. Working class jobs still carry limited potential for upward mobility and often involve physical labour, routine tasks, and a relatively dangerous or dirty environment (Willis, 1977; Roberts, 2001; McDowell, 2003). Jobs that entail physical taint (i.e. where there is direct involvement with dirt or danger) are thus commonly associated with working class men (Ackroyd and Crowdy, 1990; Ashforth and Kriener, 1999; Tracy and Scott, 2006) and, given the negative meanings associated with dirt, can pose ongoing identity threats in terms of maintaining dignity and respect (Ashforth and Kreiner, 1999; Lamont, 2000; Author 1 et al, 2012).

In the context of butchery, the daily contact with the 'powerful pollutant' of dead meat can create, from Ackroyd (2007), a 'defilement' that is difficult to assuage. Butchers must routinely deal with potentially unpleasant sights, smells and sensations: blood stains their clothing and lodges under fingernails; offal is malodorous and offensive to the touch; skills such as cutting and filleting and implements such as knives and grinders are potentially dangerous and put men's bodies at risk. As has been found in other 'dirty work' contexts, men can draw on masculine values to create positive meaning. Thus, in a study of firefighting (Tracy and Scott, 2006), men engaged in specific practices and performances that reinforced an image of the strong, heterosexual and heroic male. In butchery, men have been found to form strong occupational cultures based on aggressive realism and traditional notions of masculinity (Ackroyd and Crowdy, 1990). Slaughtermen found esteem through activities relating to strength, dominance and differentiation from women. As Meara (1974) highlighted in a study of Turkish meat cutters, honour could be found in bodily fortitude and bravery as well as in the use of knives and the ability to withstand the cold and the daily contact with blood and meat.

The occupational context of butchery is therefore potentially powerful in uncovering meanings that occupy an intersection between class, gender and dirt. We accordingly explore, in the context of changes in the trade, the meanings butchers construct around their work and the value they place on its routines, skills and practices. We do this from a perspective that sees class as a 'social space' of relations, positions, dispositions 
and meanings (Bourdieu, 1984, 1990, 1996; Skeggs, 1997, 2004a; Charlesworth, 2000). Consistent with these views, we see masculinity, rather than tied to innate endowments, as set of relations and dynamic processes of embodied practices (Martin, 2003; Connell, 1995; Whitehead, 2002) and dispositions, partly based on 'tacit knowledge and skills' (Martin, 2003: 351) that are acquired over time and 'distilled' into the axioms of self. Such practices and dispositions can be seen to make up a 'gendered habitus' (Bourdieu, 1998), negotiated and acted out according to often competing and overlapping normative gendered conceptions (Kerfoot \& Knights, 1993; Connell and Messerschmidt, 2005; Connell, 1995) within specific institutional and social contexts or fields. Masculine habitus is thus enduring and sedimentary (Lovell, 2000) but is also culturally fluid and contestable (Collinson and Hearn, 1994; Alvesson, 1998; Kerfoot and Knights, 1998; Connell, 2000) not least because no social setting remains constant and given (Whitehead, 2003).

\section{Context and Methodology}

Our research site comprised small scale 'high street' butchers working as employees in one rural and one urban area (London and Devon). Shop owners were excluded as they form a distinct, entrepreneurial group with specific experiences of the trade. Supermarket butchers were also excluded as their skill requirements (meat usually arrives at the store fully prepared) and market positioning are different from small shops. As butchers and meat-cutters, as opposed to business owners, respondents conformed to the Office for National Statistics (2010) Occupational Classification as members of a 'skilled manual trade', that is, one which requires some work-based training, rather than extended formal education. While we acknowledge challenges identifying groups according to class (see Crompton, 2010 for a discussion), all were on relatively low incomes and had left school with no (or limited) qualifications signifying a broadly working class positioning. A parallel can be drawn to the similar (though cautious) assessment made by Atkinson (2010) in his identification of the 'dominated' as a 'classed' group - a designation centring on possession of school level and/or vocational qualifications and low relative income levels.

The effects of supermarket competition are visible in the figures marking a decline in the trade. Thus, in 1980 there were 23,000 butchers premises in the UK employing an estimated over 101,000 persons. By 2008 
there were only 6,400, employing 36,000 (The Online Meat Trades Journal, 2010). At the same time, the meat trade has been subject to a series of regulations, particularly in the wake of the BSE crisis, to 'clean up' work practices, overseen by the (now defunct) Foods Standards Agency. Under the 2006 EU food hygiene legislation, regulations cover the daily cleaning and temperature monitoring of fridges, the handling of meat and where it can be displayed, and its tracking and traceability (the latter involving considerable paperwork). Here, regulations concerning the handling and traceability of meat together with a consolidation of slaughtering houses, have altered some of the skill requirements in that much of the 'heavy' (and dirty) work involving animal carcasses - and of course the killing of the animals - are now undertaken prior to the meat's arrival at the shop.

Interviews took place with 26 butchers, all of whom were male and aged between 19 and 65 . All but five were, or had been, married and had children. Most had entered the trade straight from school at the minimum school leaving age (a common route was via a Saturday job as teenager) and for these men butchery had been their only job. None of the participants had seriously considered a change of occupation and all anticipated working in the trade until retirement age. Interviews, which took the form of collaborative discussion or 'dialogue' (Alvesson and Skoldberg, 2000) were conducted in local cafés, pubs and occasionally at the back of the shop. Interviews explored several broad themes. These concerned: the occupational journeys of men in the trade; opportunities presented and choices made; the daily routines of the job; the skills drawn on and developed; aspects of the work they found most challenging and those they enjoyed.

Interviews were recorded and transcribed in full. Careful reading of transcripts was undertaken by the three authors so that familiarization could take place. Data were then organized under the broad areas identified above, after which more detailed thematic analysis took place. This was undertaken by each author separately in the first instance with later corroboration given to emerging themes by comparing and discussing, in a reflexive manner, individual insights and interpretations in the manner of Hruschka et al.'s (2004) model for the development of inter-coder agreement and reliability. This analytical process facilitated 
the identification of 'patterns of experiences' based, from Taylor and Bogdan, on 'conversation topics, vocabulary, recurring activities, meanings, feelings' (Taylor and Bogdan, 1984, p.131). Accordingly, a vocabulary of acceptance and endurance emerged from discussions of the less pleasurable aspects of the job; from attitudes of inevitability and from approaches to opportunity and choice as inapt and/or inappropriate. Such meanings permeated nearly all accounts of journeys into the trade, while narratives of loss (of skills, of dirt) were endemic to discussions of the physical character of the job. Finally, comparisons were made across the slices of data via axial coding in order to elucidate the inter-relationship between themes, identify core and recurring themes, and then to explore the extent to which such themes might be indicative of more generalized phenomena. For example, from this stage, discourses of acceptance and attitudes of inevitability were found to pervade accounts of job choice, hopes and aspirations, day-to-day routines as well as the physicality of the work.

Reflexive engagement during interviews was based on the acknowledgment of the socially contingent character of knowledge and the representation of data (Cunliffe, 2003). Thus, intrinsic power dynamics of the research were a central consideration. Following, Karnieli-Miller et al. (2009), interviewers sought to allow participants 'voice' and 'dignity' through the development of a reciprocal and democratised research encounter which also gave theoretical direction and methodological discipline. Here, in recognition of the influence of relative social positioning (e.g. between participant and researcher)on modes of understanding we sought to develop a 'deep attentiveness' (Charlesworth, 2000) based on an engaged, committed, interaction in which one 'helps the other to articulate the pieces that have contributed to the totality of their experience' (Charlesworth, 2000: 144). Employing this model of reflexive engagement helped us to elucidate facets of occupational distance as well as gender difference (two of the researchers were female). In terms of the latter, while feminist researchers (e.g. Evans, 2002) suggest women can offer a 'truer understanding' of men and masculinity on the grounds that their marginalised position means they are less 'imprisoned within established epistemological theoretical and methodological frameworks' (Frank, 1993: 337 cited in Evans, 2002), we nevertheless sought to overcome potential problems by conducting interviews in pairs and with 
the male researcher present.

In this way, through 'active listening' and an acute awareness of the potential influence of gender difference and of our own privileged occupational position, we sought to afford voice to butchers' experiences in a context where, as Schwalbe and Wolkomir (2001) argue, male working class voices are rarely heard. From this undertaking, three interrelated themes were elucidated which capture some of the meanings butchers give to their work: notions of sacrifice, erosions of physical capital and distinctiveness.

\section{Notions of Sacrifice: Choice, Acceptance and Physicality of Work}

Reflective of a context shaped by limited potentialities, few butchers had made what could be seen as an 'active' job choice. Removed from middle class orientations towards carefully thought out career structures based on personal development, mobility and agency (Skeggs, 2004a; Adkins, 2002), butchers drew in largely uncritical tones on discourses of acceptance and constrained opportunity (as one butcher commented, prosaically, "I don't mind cutting up animals - so I got a butchers job"). As Atkinson (2010) points out drawing on Bourdieu (1990), options are prompted by a set of experiences that manifest in a tacit practical sense of what is possible or achievable - representative of a classed habitus that is related to the field of potentialities. Perhaps in reflection of this, discussions around alternatives, choice and possibility (e.g. in response to the question: 'Is there a job you might have preferred?') were often faltering and unsure. "Never thought about it" was a typical response:

“...I think I would be, I don't know, I don't know really this is the only job I've ever done so it's... I haven't really thought about what I would have been..."

The stop-start sentence structure and final admission of the possibility of a provisional self ("what I would have been") have an undercurrent of pathos in the recognition of opportunity closed off and limited experience ("the only job I ever done"). As Bourdieu (1984) suggests, structures of necessity and of repressed dispositions justify acceptance of work's limitations and evoke an instrumental ethos towards work and its practices constitutive of a limited 'field of possibles' (Bourdieu, 1984) that present from the resources possessed. Here, the inevitability and inescapability of work, potentially reflective in Bourdieusian terms of the centrality of habit in engagements with the world, were rarely problematised or subject to close scrutiny: 
"You soon harden up to it (the work) you soon realize that it's just life and you know...it could be worse..."

"I just get up and go to work, go and do it, I don't look forward and I don't dread it if you see what I mean, I'm just programmed to get up and do it"

"Well it's get on and do what you've got to do isn't it? It was a job weren't it? I left school and went straight into work the next day...15 and that's it. That's all I've done ...it's OK yeah, it's all right. I don't mind you know if you don't work you don't get nothing, you know...it's long hours but l've always done it..."

As Willis (1977) found from his early study of working class men, job choices are often made by accident with little meanings attached to different types of work. Instead, despite acknowledgement of its limitations ("that's all l've done"), value is attached to employment per se ("it's a job..."). Here, particular pride was taken in occupational longevity where continuity and effort were presented as integral to notions of work, carrying traditional meanings of resilience and discipline. As exemplar, one recalled his father's experience:

"Father worked from when he was $11 . .$. He really worked and worked and worked, never had a break, never stopped... basically we did the same".

The ability to endure the physical demands (e.g. the need to process heavily resistant pieces of bone and meat; to work in refrigerated conditions for long periods of time) and to incorporate the viscerality of the product (the blood, the flesh, the smells) into day to day work practices were accepted as integral to the job. All butchers claimed to have got "used to" these demands which, in Ackroyd and Crowdy's (1990) terms, could be a source of pride. Reflecting a primacy placed on 'physical capital' (Wacquant, 1995) where the body is inscribed with value through physical force and prowess, the physical aspects of the work were carefully described and all butchers made reference to the stamina required:

"...the sheer weight of things, you know, to do the job you are required to lift and even, sort of, if you've got a quarter of a cow put in front of you, even pulling the muscles back to separate things, it's 
very, very hard"

Many were able to able to recount, with some precision, the weight of the carcasses they carried, intimating pride in their stamina and strength as well as in the skills acquired:

"... a side of pork can weigh fifty kilos, but you know a quarter of beef is a hundred kilos, 110 sometimes...but if you carry it right, if you are trained, yeah, but you're trained you can carry it to the point where you don't, you don't feel it..."

"I can cut it (a lamb) in seconds, you know, literally seconds. It's only experience but I'm still careful what I do. I don't like, I don't make a mess of it, it's a proper job, you know, because that's the way I've been trained" Physical competence, prized within the norms and values of traditional working class masculinity (Willis, 1977; Connell, 2000; MacDowell, 2003) therefore gives meaning to work through dignity and respect as well as through endurance and acceptance of work's conditions (Sennett and Cobb, 1972; Skeggs, 2004a Connell, 2000; Thiel, 2007). At the same time, while it was universally rejected as unsuitable for children (too arduous, too constraining), the work was valued for providing a living wage and support for families - particularly the opportunity given by a regular income to sons and daughters in pursuing their chosen careers (many of whom were educated to university level and had white collar jobs).

"Income was the most important thing...and now my son's growing up. He has aspirations to do other things, he quite likes the fact that I do this...he is not squeamish about it. He enjoys good meat...but no, he's got aspirations to do something more, you know"

"And that's when you find... when you need to provide for your family. It's long hours, hard work, not great rewards. But (with children) you start looking at things differently....and looking at them now l'd say I've done OK..."

"People think it's a hard job ...but I've supported my step daughter through college" 
Here, effort, endurance and limited rewards are supportive, through breadwinner discourses, of meanings relating to sacrifice and self-denial. Thus, in a social context characterized by constrained opportunity and where work's limitations are recognised, working class men give their families the material means for a 'better life' that encompass futurity in the hopes and dreams that they carry for others - reflective of a habitus that is directed via the conversion of capital towards future accrual. Thus, in the face of limited power to gain respect and while the job was seen as unworthy of children, the recipient of the offering made, effort and endurance can give work meaning through the future chances it allows. This points to continuity of meanings, reproduced as part of a working class habitus which, as Bourdieu (1992) suggests, carries traces of past history and facilitates acceptance and reconciliation to the implications of social locations. Thus, as others have found, (e.g. Sennett and Cobb, 1972; others) men draw on traditional breadwinner discourses that are imbued with attitudes of self-denial to give meaning to work. As a 'materialization' of class taste (Bourdieu, 1984) that reveals the 'deepest dispositions' of the habitus, the symbolic meanings attached to physical capital can be seen to reflect and reproduce the 'universe of the social structure' (Bourdieu, 1984; 193) within the working class experience.

\section{Changing Work Practices and Erosions of Physical Capital}

Despite the meanings attached to effort and endurance outlined above, changes in the meat industry increased regulation and a decline in the 'small shop' trade - have combined to alter the nature of work practices and to place less primacy on bodily skills and strength. This 'cleaning up' and regulation of the trade have served to erode the significance of physical capital discussed above and were interpreted through narratives of loss and regret - provoking nostalgia for the old, dirtier ways:

"We used to truss our own chickens, which now we're not allowed to. So you'd have blood and guts and half-digested food on your hands and you'd just go (shakes hands as if to dislodge dirt) and then you'd cut rump steak for someone, which I can understand is not hygienic - but we lived..." Such displays of casual realism may be symptomatic in Bourdieusian terms of a reality principle, driven by necessity and antithetical to sentimentality, that imbues the working class habitus. All interviewees expressed some form of regret over the erosion of physical skills and the loss of heavy, dirty work: 
It's always been a physical job...that didn't bother me. And then sort gradually over the year's it's become, you know, you are more like an office worker now than a butcher. Everything has to be recorded...It's become sort of, yeah, it's too clinical.

Here, processing larger and heavier sides of beef had been particularly prized. In fact, beef was the common reference point in butchers' accounts of descriptions of their trade and used in general as exemplars of meat. The tendency for beef carcasses to be cut and processed at the slaughterhouse rather than at the butcher's shop was accordingly a source of regret:

"although it was... harder work, there's a lot more harder work when I was younger i.e. busting up more (beef) carcasses which I used to enjoy doing"

As Sennett and Cobb (1972) argue, working class men can resist the devaluation of class by elevating their physical abilities so that the capability to endure the physicalities of the job is a source of masculine pride. The erosion of physicality within work practices can accordingly bring masculine identities under threat as lighter lambs replaced weightier beef and as 'nicely packed' meat (sanitized, aesthetic) substituted (masculine) skill and knife work.

"A hundred and forty pounds. A hundred and ninety's the biggest (beef) I've carried! Now it's sort of lamb is about the biggest I carry..."

"We used to bring it (beef carcass) back on the van and that was hard work and it wasn't very, it was a low van, sometimes you had to lift it. Oh my, you know, but those days are all gone now, so it all comes packed nicely"

Read through Bourdieu (1984), in integrating past experiences, the habitus functions as a 'matrix' of perceptions, appreciations and actions such that we are 'carriers of our history' (Skeggs, 2004b). The past accordingly structures the present and, in this respect, a prior premium placed on physical capital that gave meaning to work, can translate into the present in the form of loss and regret and open up, potentially, vulnerability in terms of how masculinity in the context of such work is experienced. Further, disruptions caused by a devaluing of skills and capacities within a social field can, as Shilling (2004) proposes, lead to 
reassessments and revaluations of attitudes and behaviours.

\section{'Authentic' Trade Practices and Distinctiveness}

These expressions of loss and regret can be located within particular regimes that mark the decline and regulation of the trade as well potential challenges to men's (gender and class based) positioning. Here, the erosion of prized physical skills and a devaluing 'dominant symbolic' (Skeggs, 2004) that positions the working class as undeserving can, potentially, impress painfully of the sense of self. This was partly manifest in attitudes of self-deprecation (as one butcher cheerfully commented of his supposed suitability for the trade: "I'm pig ignorant, me") and a general acknowledgement that the job was seen as having little value. However, positive meaning was mobilized through the creation of distinctiveness from supermarket trade.

Here, solace could be found in the meaning attached to shared membership of a trade both as a source of regular income, of a sense of belonging and of a valued distinctiveness through possession of specialist knowledge and skills. Thus, butchers saw themselves as 'authentic practitioners' and 'champions' of what one described as a "dying art", enjoying a shared camaraderie in the closed space of the shop and a good natured competitiveness e.g. over speed and dexterity in breaking down a large piece of meat. This was positioned against supposedly 'inferior' supermarket meat processing based on the mass production of largely undifferentiated cuts of cheap meat. Traditional trade practices of the small butcher were valorized and their ownership claimed:

"We hang our beef for 28 days - if you go to a supermarket it's literally been killed one day and it's in the cabinet the next".

"You see they're not real butchers in a supermarket. A lot of their stuff all you need is a Stanley knife, open the box and put it out...they haven't got the same skills as we have"

“I can do a vast range of things - not just counter presentations (as in supermarkets) you don't get many 
butchers like that in this day and age"

In creating distinction from 'non-genuine' trade practices ("they're not real butchers") respondents claimed authentic belonging to the trade and a rarity value through specialist knowledge regarding the provenance of

meat, the different cuts and how to bone, cook and prepare it.

"Everything is done to the highest standard...if you were to buy something like that from (supermarket) or somewhere like that you would find that the piece of meat would have sinew in it, it would have fat that somewhere like ourselves who are working to a premium product will remove".

“You don't just pick up a bit of meat and we know where the meat's come from, what to do with it...we're really part of the cooking.. you need to be a bit of a chef as well"

The recent rise in TV cookery programmes and of 'celebrity chefs' were seen to have infused the trade with new value based on a passion for quality food and on specialist knowledge ("what they say is, go talk to your butcher"). Personal service and the relationship with customers, often based on banter and shared humour, was a further source of differentiation and many referred with pride to an increasingly discerning customer base where quality was appreciated and where advice was sought on the cut of meat as well as methods of preparation. Meaning was therefore found in constructions of shared and 'genuine' practices of butchery based on a distinction from supposedly less authentic supermarket trade as well as, relatedly, from proximity to newly celebrated (and masculinized) culinary skills. As Bourdieu (1996) suggests, individuals distinguish themselves from others through 'symbolically meaningful position taking' (Emirbayer and Johnson, 2008) that derives significance from difference. Butchers accordingly mobilise and create meanings based on distinctiveness that have, as their origin, specific changes within the structural setting of the industry and of the trade. 


\section{Discussion}

This article set out to explore the meanings that butchers as members of a 'dirty', manual trade, give to their occupation in the context of widespread changes in the industry and in work practices. We find that butchers adhere to traditional notions of work as hard, on-going and inescapable. Relatedly, attitudes of acceptance and practices of reactivity emerged in discussions of options and choice where men had difficulty engaging with potential, possibility and alternatives. Instead, endurance and fortitude were key resources in managing the physical demands and the 'dirty' nature of the job - comprising together with the practice of skills, a source of pride. Recent regulation and changes in the butcher trade have, however led to a devaluation of physical capital - reflective of its contingency to the structure of the field in which it is deployed (Bourdieu and Wacquant, 1992). Butchers mourn the loss of weighty loads as beef is processed offsite; they dwell on the physical endurance that was required; they regret the bureaucratization that has removed practices and aspects of dirt; they experience as loss the heavy knife work that was involved - prompting, as Shilling suggests in the context of disruption in the 'norms and structures' of a social field (Shilling, 2004: 481), 'breaks' in habitual action and potential reassessment of meanings attached.

Such reassessments can be seen to be both reproductive and productive as butcher reinforce historically grounded evaluations of work and mobilise new meanings in response to changes in the trade. In terms of the former, despite a reduced emphasis on physical capital in practices of work, butchers adhere to traditionally masculine working class notions of sacrifice, endurance and continuous hard work as 'offerings' for the welfare of families and place emphasis on the discomfort and constraints endured. Thus, 'getting used to' the cold, the heavy loads and the dirt demands bodily endurance that is traditionally tied to a classed and gendered bodily aesthetic where 'manly readiness' has historically provided working class men with selfesteem (Willis, 1977; Sennett and Cobb, 1972). In Bourdieusian terms, this highlights the significance of personal and collective history embedded in the structure and ethos of a defined social habitus that in this context supports and valorises a sacrificial self in the form of a voluntary self- denial. Further, the discourses of acceptance and sentiments of inevitability that butchers convey may reflect, as Bourdieu (1980) suggests, 
the 'repressed dispositions' associated with a working class habitus where the inculcation of perceptions and values offers 'reconciliation' (Bourdieu, 1980) to structural conditions and which may give an added dimension, through potential and possibility, to the sacrifices made. Thus, in reflection of a habitus that is also oriented towards future accrual, dirty, manual work can enable futurity in the potential that sacrifice conveys where, within a social context of limited possibility (ref), children implicitly repay and acknowledge the sacrificial act by opening up the prospective (through more promising careers) - the very resources that butchers have been denied. Sacrifice and self-denial may therefore give value and meaning to work and help explain traditional orientations based on effort and occupational longevity as well as attitudes of acceptance and inevitability that permeate butchers' accounts. Such meanings attached to physical capital persist despite erosions within work practices and associated feelings of loss and regret - indicating how new experiences are 'perceived through categories already constructed by prior experiences' (Bourdieu, 1992: 133) and how meanings can accordingly be reproduced.

At the same time, butcher mobilise and create meanings based on authentic belonging and on a positive distinctiveness in the face of intense competition from supermarket trade - signifying the field as a terrain of contestation between occupants that are 'differentially endowed with the resources necessary for gaining and safeguarding an ascendant position within that terrain" (Emirbayer and Johnson, 2008: 6). Within this space of position taking - as a contextually based set of 'objective potentialities' (Bourdieu, 1996) that are delineated by the conditions of the field - butchers infuse their shared knowledge and skill with valued distinction and borrow creatively from a celebrated culinary ethos and on its notions of professional practice to construct and retain a 'semiotic structure of difference'. The space of position taking thus contains creative potential and butchers reinvigorate skill with meaning through a valued distinctiveness and borrow strategically from contemporary, media endorsed discourses of (newly masculinized) cuisine.

Drawing on Bourdieu, this article has contributed to our understanding of working class masculinity, a neglected area within organization studies, by showing how dirty, manual work can open up meanings relating to sacrifice 
and self-denial as integral to an enduring gendered, working class habitus and can offer potential to create distinctiveness through symbolically meaningful position taking. Through the disruptions caused by an erosion of physical capital in the context of a highly regulated and declining trade, butchers both cling to dispositions that have traditionally afforded meaning and create new forms of value and distinctiveness. With the primacy afforded, in butchers' accounts, to traditional breadwinner roles as well as to claims of 'authentic 'practices compared to supermarket trade, notions of sacrifice and of 'authentic distinctiveness' can provide a basis for understanding both the reproduction and production of meanings that butchers give to their work. We have shown, along the lines of Bourdieu, how meanings and judgements are integral aspects of an emergent social habitus that has shifted with the structure of relationships in which it is founded. Further, rather than orienting towards a continuity of meanings based 'internalization' of class based structures (Wacquant, 1992), we have shown through our research site how the habitus involves simultaneous social reproduction and reproduction as meanings draw on historical precedent and can be seen to be actively asserted and, effectively, 'carved out of' a social and cultural field. 


\section{References}

Ackroyd, S. (2007) 'Dirt, Work and Dignity', in S. Bolton S (ed) Dimensions of Dignity at Work. Amsterdam: Elsevier, $30-51$

Ackroyd, S. and Crowdy, P. (1990) 'Can Culture be Managed? Working with Raw Material: The Case of the English Slaughterhouse Workers, Personnel Review 19(5): 3-14.

Adams, C. (2010) The Sexual Politics of Meat: A Feminist Vegetarian Critical Theory, London and New York: Continuum International Publishing

Adkins, L. (2002) Revisions: Gender and Sexuality in Late Modernity. Buckingham: Open University Press. Alvesson, M. and Sköldberg, K. (2000) Reflexive Methodology: New Vistas for Qualitative Research. London: Thousand Oaks.

Ashforth, B. and Kreiner, G. (1999) “How Can you Do it?" Dirty Work and the Challenge of Constructing a Positive Identity, Academy of Management Review 24(3): 413-434.

Ashforth, B., Kreiner, G., Clark, M. and Fugate M. (2007) Managerial Tactics for Countering Occupational Taint, Academy of Management Journal 50 (1): 149-174.

Atkinson. W. (2010) Class, Individualization and Late Modernity: In Search of the Reflexive Worker. New York: Palgrave Macmillan.

Beck, U. (1992) Risk Society: Towards a New Modernity. London: Sage Publications.

Bolton, S. (2007) Dimensions of Dignity at Work. Amsterdam: Elsevier.

Bourdieu, P. (1984) Distinction. London: Routledge.

Bourdieu, P. (1998) La Domination Masculine. Paris: Seuil

Bourdieu P (1990) The Logic of Practice. Cambridge: Polity Press.

Bourdieu, P. (1996) Understanding. Theory Culture and Society 13(2): 17-37

Bourdieu, P. and Wacquant, L. (1992) An Invitation to Reflexive Sociology. Chicago: University of Chicago Press. 
Charlesworth, S. (2000) A Phenomenology of Working Class Experience. Cambridge: Cambridge University Press.

Collinson, D. (1998) 'Engineering Humour': Masculinity, Joking and Conflict in Shop-floor Relations' Organization Studies, 9 (2): 181-199

Connell, R. (2000) The Men and the Boys. Cambridge: Polity Press.

Crompton, R. (2010) Class and employment. Work, Employment \& Society 24(1): 9 -26.

Cowen, R. and Bochantin, J. (2011) 'Blue-Collar Employees' Work/Life Metaphors: Tough Similarities, Imbalance, Separation and Opposition', Qualitative Research Reports in Communication, 12(1): 19-26 Cunliffe, A. (2003) 'Reflexive Inquiry in Organizational Research: Questions and Possibilities. Human Relations 56(8): 983-1003.

Dick, P. (2005) 'Dirty Work Designations: How Police Officers account for their use of Coercive Force', Human Relations 58(11): 1363-1390.

Douglas, M. (1966) Purity and Danger: An Analysis of Concepts of Pollution and Taboo. London: Routledge. Gabriel, Y. (2005) ‘Glass Cages and Glass Palaces: Images of Organization in Image-conscious Times', Organization 12(1): 9-27.

Giddens, A. (1991) Modernity and Self-Identity: Self and Society in the Late Modern Age. Stanford, Calif.: Stanford University Press.

Gregg, P. and Wadsworth, J. (2003) 'Labour Market Prospects of Less Skilled Workers over the Recovery', in Dickens, R., Gregg, P. and Wadsworth, J. (eds) The Labour Market Under New Labour: The State of Working Britain. Basingstoke: Palgrave Macmillan, 86-98

Hruschka, D., Schwartz, D, St. John, D, Picone-Decaro, E, Jenkins R and Carey, J. (2004) 'Reliability in Coding Open-ended Data: Lessons Learned from HIV Behavioural Research', Field Methods 16(3): 307-331.

Hughes, E. (1951) 'Work and the Self' in J. Rohrer and M. Sherif (eds) Social Psychology at the Crossroads. New York: Harper and Brothers, 317-371

Hughes, E. (1958) Men and Their Work. Glencoe, II: Free Press. Isaksen, J. (2000) 'Constructing Meaning despite the Drudgery of Repetitive Work, Journal of Humanistic 
Psychology 40(3): 84-107

Jahoda, M. (1982) Employment and Unemployment: A Social Psychological Analysis. Cambridge: Cambridge University Press.

Karnieli-Miller, O., Strier, R. and Pessach, L. (2009) 'Power Relations in Qualitative Research', Qualitative Health Research 19(2): 279-289.

Lamont, M. (2000) The Dignity of Working Men: Morality and the Boundaries of Race, Class and Imagination. New York: Russell Sage Foundation and Harvard University press.

McDowell, L. (2003) Redundant Masculinities: Employment Change and White Working Class Youth. Oxford: Blackwell

Meara, H. (1974) 'Honor in Dirty Work: The Case of American Meatcutters and Turkish Butchers, Work and Occupation 1(3): 259-273.

Nixon, D. (2009) “I can't put a Smiley Face on": Working Class Masculinity, Emotional Labour and Service Work in the 'New economy'. Gender Work and Organization 16(3): 302-322

Noon, M. and Blyton, P. (2007) The Realities of Work: Experiencing Work and Employment in Contemporary Society. Basingstoke: Palgrave Macmillan.

Office for National Statistics (2010) Standard Occupational Classification. Available at http://www.ons.gov.uk/ons/guide-method/classifications/current-standardclassifications/soc2010/index.html

The Online Meat Trades Journal (2010) Available at: http://www.meatinfo.co.uk

Overell, S. (2009) The Meaning of Work. London: The Work Foundation.

Roberts, K. (2001) Class in Modern Britain. Basingstoke: Palgrave.

Sayer, A. (2005) The Moral Significance of Class. Cambridge: Cambridge University Press.

Schwalbe, M. and Wolkomir, M. (2001) 'The Masculine Self as Problem and Resource in Interview Studies of Men, Men and Masculinities 4(1): 90 -103.

Sennett, R. (1998) The Corrosion of Character: The Personal Consequences of Work in the New Capitalism. New York: Norton. 
Sennett, R. and Cobb, J. (1972) The Hidden Injuries of Class. Cambridge: Cambridge University Press.

Skeggs, B. (1997) Formations of Class and Gender. London: Sage.

Skeggs, B. (2004a) Class, Self and Culture. London: Routledge.

Skeggs, B. (2004b) Context and background: Pierre Bourdieu's analysis of class, gender and sexuality. The Sociological Review 52(2): 19-33.

Taylor, S. and Bogdan, R. (1984) Introduction to Qualitative Research Methods: The Search for Meanings. New York: Wiley.

Thiel, D. (2007) Class in Construction: London Building Workers, Dirty Work and Physical Cultures, The British Journal of Sociology 58(2): 227-251.

Thompson, E.P. (1991) The Making of the English Working Class. London: Penguin Books.

Tracy, S. and Scott, C. (2006) Sexuality, Masculinity and Taint Management among Firefighters and Correctional Officers: Getting Down and Dirty with "America's heroes" and the "Scum of law enforcement". Management Communication Quarterly 20(1): 6-38.

Turner, B. (1996) The Body and Society. London: Sage.

Wacquant, L. (1995) Pugs at Work: Bodily Capital and Bodily Labour among Professional Boxers, Body and Society $1(1): 65-93$

Willis, P. (1977) Learning to Labour: How Working Class Kids get Working Class Jobs. London: Hutchinson. Wray-Bliss, E. and Parker, M. (1998) 'Marxism, capitalism and ethics' in M. Parker (ed) Ethics and Organizations. London: Sage, 30-52

Wrzesniewski, A. and Dutton, J. (2001) ‘Crafting a Job: Revisioning Employees as Active Crafters of their Work, The Academy of Management Review 26(2): 179-201. 